SABIO, G.C., et al, (2006). Preservation of Mestizo 1 (PSB Rc72H) seeds using hermetic and low temperature storage technologies. In: Lorini I, et al., (eds). Proc. $9^{\text {th }}$ Int. Working Conf. Stored Prod. Prot. Campinas, Sao Paulo, Brazil, ABRAPOS, (2006): 946-955. spiru.cgahr.ksu.edu/proj/iwcspp/iwcspp9.html

VILLERS, P., DE BRUIN, T. and NAVARRO, S., Development and applications of the hermetic storage technology. 9th Int. Conf. on Stored Product Protection, Sao Paulo, Brazil, ABRAPOS, (2006): 719-729.

WALIYAR, F., et al, (2013). Pre- and postharvest management of aflatoxin contamination in groundnut. USDA/USAID Int. Aflatoxin-in-Maize Working Group, New Orleans, LA, USA.

WILLIAMS, J. H., et al, (2004). Human aflatoxicosis in developing countries: a review of toxicology, exposure, potential health consequences, and interventions. American Journal of Clinical Nutrition, 80, 1106-1122.

WILLIAMS, J. H., (2011). Aflatoxin as a public health factor in developing countries and its influence on HIV and other diseases. Peanut Collaborative Research Support Program, University of Georgia. World Bank Report \#60371-AFR, 1-95.

ZORYA S., et al, (2011). Missing food: The case of postharvest grain losses in sub-Saharan Africa. World Bank Report \#60371AFR; 1-95.

\title{
Establishing the value of modern seed storage methods for wheat in diverse production ecologies in Nepal
}

\section{Mina Devkota', Krishna Devkota' ${ }^{2}$, Andrew J. McDonald'}

${ }^{1}$ International Maize and Wheat Improvement Center (CIMMYT), Nepal

${ }^{2}$ International Rice Research Institute (IRRI), Nepal

DOI 10.5073/jka.2018.463.139

\begin{abstract}
In the developing-country context of Nepal, farmers often incur in seed losses of $15-30 \%$ due to improper storage. To evaluate the efficacy and costs of modern storage alternatives, experimental trials were set up among ten farmers each in two contrasting ecologies, i.e. Palpa (hills) and Rupandehi (terai plains) districts of Nepal in 2013. Several wheat seed storage options were contrasted including farmer practices (FP) such as reused fertilizer bags, polythene bags, household metal containers, and mud bins. Modern storage methods that were evaluated included plastic bags (with and without pesticide), metal bins, and hermetic 'SuperGrainbag' (SGB). Seed quality and losses were assessed after six months of storage (May-October) with parameters such as grain moisture content, insect damage, seed germination, and seedling vigor. The overall quality of seed with FPs was lower in the hills than in the terai plains. Among the treatments, SGBs were more effective in maintaining acceptable seed moisture levels, controlling insect damage $(<1 \%)$, preserving germination $(>90 \%$ lab, $>65 \%$ field), and promoting seedling vigor. Metal bins and plastic bags without pesticide had higher insect damage (7$15 \%)$ compared to FP and plastic bags with pesticide (2-5\%). In terms of storage costs, SGBs were comparable with the farmers' storage methods ( $\$ 5-6$ per $100 \mathrm{~kg}$ seed storage). Our findings demonstrate that SGBs are better at maintaining seed quality and more economical than not only FP but also the other modern storage methods evaluated in this study across different production ecological regions in Nepal.
\end{abstract}

Keywords: SuperGrain bag, seed quality, germination, insect infestation, seed moisture.

\section{Introduction}

As a versatile crop, wheat is an essential part of the diet and food trade in many parts of the world (Uthayakumaran and Wrigley, 2010). In Nepal, wheat is the third most important cereal after rice and maize in terms of area and production. Moreover, it is widely adopted across the country with cultivation ranging from 50 to $4000 \mathrm{~m}$ in elevation. It shares $16 \%$ of the total calorie and $20 \%$ of the total protein supplied from plant products in diets of both the hills and plains in Nepal (CBS, 2015). The plains share $55 \%$ of the wheat area and contribute $62 \%$ to the total production, compared to $45 \%$ and $38 \%$, respectively, by the hills (NARC, 2017).

Good quality seed is considered as the most basic and cheapest, yet most critical input for enhancing productivity (Rana, 1997). However, in Nepal, the seed replacement rate for wheat is only $13 \%$ (GoN, 2013). Only $15-20 \%$ of the total quantity of wheat seed required for planting is supplied by seed producing agencies that have proper storage structures (warehouses) with moderate cooling and periodic drying facilities. The majority of the seed is exchanged among farmers and stored at room temperature in various kinds of storage materials such as plastic or fertilizer bags, and small to medium sized metal bins, with or without pesticides (FGD, 2013). Seeds, being hygroscopic in nature, are prone to changes in moisture content in response to weather, which 
ultimately affects their quality during storage (Ellis and Roberts, 1980). High temperature, seed moisture content and relative humidity during storage as well as poor on-farm storage facilities are the key reasons that lead to insect and mold infestation. Insect and pest damage are effectively responsible for most of the decline in quantity, quality, and germination potential of stored seed (Olakojo and Akinlosotu, 2004). In Nepal, grain storage losses due to insect-pests, rodents and mold range from $15-30 \%$ annually (K.C., 1992). Thus, knowledge on proper seed and grain storage methods is important to minimize these storage losses (Kibar, 2015).

The use of hermetically sealed bags such as SuperGrain bags (SGB) (GrainPro, 2017) and Purdue Improved Crop Storage (PICS) bags have been reported as alternative storage options to maintain quality of stored seeds and grain for many crops in Africa and South Asia (Afzal et al., 2017; Baoua et al., 2012; De Groote et al., 2013; Murdock et al., 2012; Mutungi et al., 2014; Vales et al., 2014). Hermetic storage refers to a modified atmosphere of low oxygen and high carbon dioxide $\left(\mathrm{CO}_{2}\right)$ content created by respiration of living organisms such as insects. It is designed to protect stored agricultural commodities such as seeds, cereal grain, pulses, and coffee (Baributsa et al., 2014; Chigoverah and Mvumi, 2016; Navarro, 2006; Villers et al., 2010).

In Nepal, the storage season for wheat seed (May-October) is wet and humid, with $>90 \%$ of the annual rainfall occurring during this period. Thus, preventing post-harvest losses while maintaining seed quality is a major challenge for small holder farmers in both the hills and plains. There is a need for economically feasible, less labor intensive, safe (no use of chemicals) and convenient (easy to transport) storage technology that would benefit farmers and reduce losses. The present study was therefore conducted to evaluate the performance of alternative storage devices in maintaining seed quality of wheat as well as being economically competitive with farmers' traditional storage practices in climatically and geographically distinct areas.

\section{Materials and methods}

\section{Experimental sites}

The experiments were conducted at two sites, Palpa (Madiphat) and Rupandehi (Basantapur and Dhagdahi), selected based on different ecology and climatic conditions. Madiphat lies in the midhills of Palpa at an altitude of $800 \mathrm{~m}$, and has a cool but humid climate with annual rainfall of 1513 $\mathrm{mm}$ and temperature of $20.5^{\circ} \mathrm{C}$ on average. Rupandehi lies in central terai plains at an altitude of 99 $\mathrm{m}$, and has a hot and humid climate with annual rainfall of $1762 \mathrm{~mm}$ and temperature of $25^{\circ} \mathrm{C}$ on average. In both areas, over $85 \%$ of the total annual rainfall occurs in the four months of JuneSeptember (Fig.1) (MoSTE, 2014). 


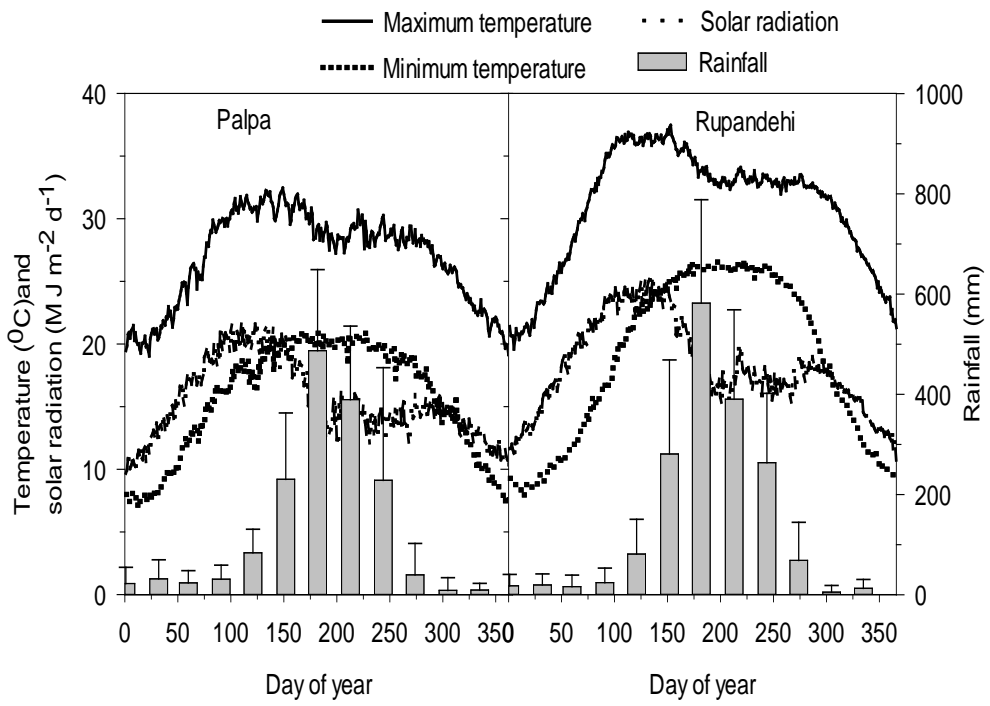

Fig. 1 Daily maximum and minimum temperature, solar radiation and the monthly total rainfall in Madiphat, Palpa and in Rupandehi. Data from long term average from 1987-2013 in Palpa and from 1977-2013 in Rupandehi. The vertical bars are the standard deviation. Source: (MoSTE 2014).

Experimental details and treatments

A participatory experiment was established in ten different wheat cultivating farmers' storage houses each in Rupandehi (terai plains) and Palpa (hills) in 2013. Five types of storage materials were evaluated at each site, i.e. traditional farmers' practice (FP), plastic bag with pesticide (celphus: a common pesticide used for storage pests), plastic bag without pesticide, metal bin and SuperGrain bag (GrainPro, 2017). Individual farmers were considered as replications; hence, each treatment was replicated 10 times in both sites.

Wheat variety NL-297 was used for storage in all the treatments. Prior to storage, the seeds were dried down to at least $12 \%$ moisture and then cleaned by removing all the broken seeds and other inert material. The storage duration was six months (May-October), i.e., after wheat harvesting (April) to before wheat seeding (end of October). Twenty kg of seed was stored in each storage treatment except FP, where samples were taken from the farmer's storage method.

The metal bins were fabricated from gauge 24 galvanized metal sheets $(0.51 \mathrm{~mm})$ by locally trained tinsmiths and had a seed holding capacity of $30 \mathrm{~kg}$. Plastic bags with dimensions of $80 \mathrm{~cm}$ (height) by $50 \mathrm{~cm}$ (width) and seed capacity of $50 \mathrm{~kg}$ were bought from the local market. Celphus was applied only once to the selected plastic bags at the beginning of the experiment. The SGBs were purchased from Mero Agro Pvt. Ltd. (Kathmandu, Nepal), a local product distributor of GrainPro, Inc. (Zambales, Philippines). These bags are manufactured using high density polyethylene that essentially reduces gas exchange from the stored product. After filling the bag with seed, the empty portion of the bag was squeezed to remove excess air. The opening was then closed by tightly twisting the free portion and sealing it with a special strap fastener provided with the bag. For air-tightness, the top of the bag was twisted twice, folded back and sealed with another fastener. As per recommendations, the SGBs were used as liner bags inside the polypropylene bags, which provide more support and ease in handling. The top of the outer bag was also fastened and sealed in the same manner.

Seed sampling and data collection

After six months of storage, all the treatments were taken out to an open space and the seed inside each was thoroughly mixed. From each storage treatment, two seed samples of $\sim 500 \mathrm{~g}$ and $\sim 200 \mathrm{~g}$ 
were taken to inspect for insect damage and for evaluation of seed germination and vigor, respectively. The samples were kept in clean, labeled plastic bags and transported to the laboratory. Seed moisture content: It was measured immediately after sampling using a grain moisture meter (GMK-303CF. GrainPro, Inc., Zambales, Philippines).

In the laboratory, a sub-sample of $\sim 200 \mathrm{~g}$ was taken to count for insect damage, and their number and weight were recorded. Seeds with holes and cracks in them were considered infested by insects. The count and weigh method, which is the most common method to measure loss by insects and pests in storage (Adams and Schulten, 1978), was used for insect damage assessment.

\section{Determination of seed germination and vigor}

One hundred seeds were randomly drawn per household from each treatment for the lab germination test which was conducted at the National Seed Testing Laboratory in Bhairahawa. The seed samples were placed evenly in germination paper and rolled around in it; then, they were wetted with distilled water and placed in an incubator at $25^{\circ} \mathrm{C}$ for seven days. Moisture was maintained by misting with distilled water as needed.

For the field germination test, 100 randomly drawn seeds from each treatment were sown in line (one treatment per line) in a well-prepared field with sufficient soil moisture at the National Wheat Research Program (NWRP), Bhairahawa. Germination, expressed as a percentage, was indicated by appearance of sprouts for lab seeds and seedlings coming out from the soil for field seeds. The seed vigor represents a more sensitive parameter than the germination test and aims to classify seed with higher probability to perform well after sowing and/or during storage (Marcos Filho, 2015). It was assessed based on germination percentage and seedling length, as suggested by Abdul-Baki and Anderson (1973).

Cost estimation for storage treatments.

The total cost involved in each storage treatment was calculated for storing one quintal of wheat seed. It included the cost of storage material and labor used for drying and storage for each treatment. Further, to understand the farmers' current practice for wheat storage, focus group discussions (FGDs) with 15 farmers in each group were carried out in both Rupandehi (3 FGDs) and Palpa (2 FDGs).

\section{Statistical analysis}

Data collected for different parameters were analyzed for analysis of variance (ANOVA) of completely randomized block design, considering farmers as replications using GenStat Version 18. Most variables were not normally distributed (except seed moisture content). Prior to analysis, the variables were transformed to normality using the Johnson Transformation Function of Minitab. Differences in locations and individual treatment effect were analyzed using Fisher's Protected Least Significant Difference (LSD) and treatment differences were considered statistically significant at $\mathrm{p}<0.05$. Graphical representations were made in Sigma Plot version.

\section{Results}

\section{Current farmers practice of wheat seed storage}

From the FGDs, it was found that 70-75\% farmers stored wheat seed in fertilizer bags with 2-3 times sun drying during storage, while about $15-20 \%$ farmers' stored seed in metal bin with pesticide in both Rupandehi and Palpa districts. Ten percent of farmers used other storage structures, for example, mud bin, plastic bin, or plastic containers. In FGD, it was reported that $10-90 \%$ insect damage (10-80 \% in Rupandehi, $15-90 \%$ in Palpa) occurred under the farmers' current method of storage in both districts. 


\section{Seed moisture content}

After six months of storage, seed moisture content increased significantly $(p<0.001)$ from the initial level ( 12\%) in all treatments, with greater increment in Palpa (12.9-14.8\%) than in Rupandehi (9.3$13.1 \%)$. In Palpa, a significant increase in seed moisture content was observed in plastic bags without pesticide (by $3 \%$ ), followed by plastic bags with pesticide, metal bins and farmers' practice (by $2 \%$ ), while that in SGB was $<1 \%$. In Rupandehi, the seed moisture content in SGBs and plastic bags with pesticide was unchanged, while it increased by $1 \%$ under metal bins and plastic bags with pesticide. Conversely, the moisture content dropped down to $9 \%$ under the farmers' storage practice, which could be attributed to frequent sun-drying, higher air temperature, and comparatively low rainfall (Fig. 6; Fig. 1).

\section{Insect damage}

Significant treatment effect $(p=0.01)$ was observed in the insect damage levels in both the study sites. In Palpa, insect infestation was the highest in plastic bags without pesticide (14 $\pm 3 \%)$, followed by metal bin storage $(9 \pm 2 \%)$, plastic with pesticide $(3.2 \%)$, FP $(2.4 \%)$ and SGB $(<1 \%)$ at the end of the storage period. In Rupandehi, seed stored in metal bins had the highest level of damage $(10 \pm 2 \%)$ followed by plastic bags without pesticide and farmers' method (3-4\%), while plastic bags with pesticide and SGBs were found to have negligible damage. In both the locations, seed stored in SGBs showed negligible insect infestation (Fig. 2).

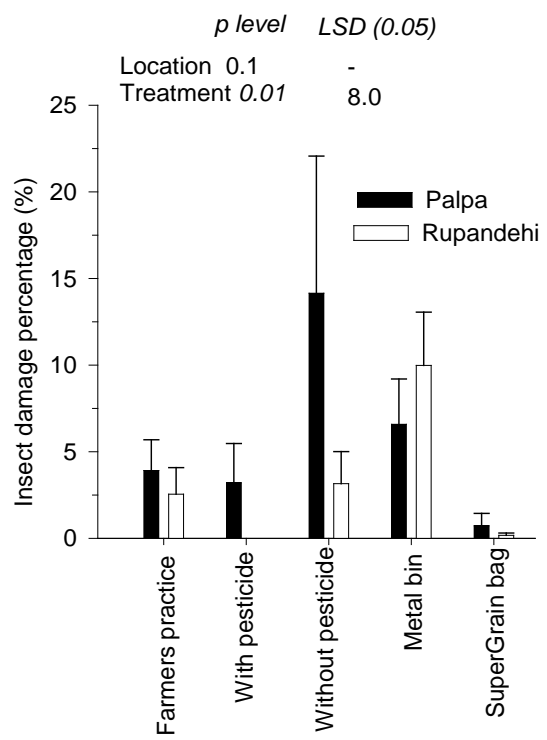

Fig 2. Variation in percent insect damage after six months storage under different treatments in Palpa and Rupandehi.

\section{Seed germination and vigor}

Seed obtained from all storage treatments in Palpa showed significantly lower $(p=0.02)$ germination percentage than in Rupandehi, which is a similar trend to that of seed moisture content (Fig. 3A). A significant treatment effect was observed in both lab and field-tested germination percentage in both locations. In Palpa, seed from plastic bags without pesticide showed the lowest germination percentage (63\% lab, $43 \%$ field), followed by metal bin storage ( $66.3 \%$ lab, $56 \%$ field), FP (69.3\% lab, $53 \%$ field), plastic bags with pesticide (75.2\% lab, 51.5\% field) and SGBs ( $90 \%$ lab, 68\% field) (Fig.3). In Rupandehi, the seed in metal bins showed the lowest germination percentage $(67 \%$ lab, 50\% field), followed by plastic bags without pesticide ( $81 \%$ lab, 54\% field), FP ( $90 \%$ lab, 56\% field) and 
plastic bags with pesticide ( $89 \%$ lab, $65.4 \%$ field). The highest germination percentage was observed in SGB storage ( $92.8 \%$ lab, $69 \%$ field) as seen in Figure 3.

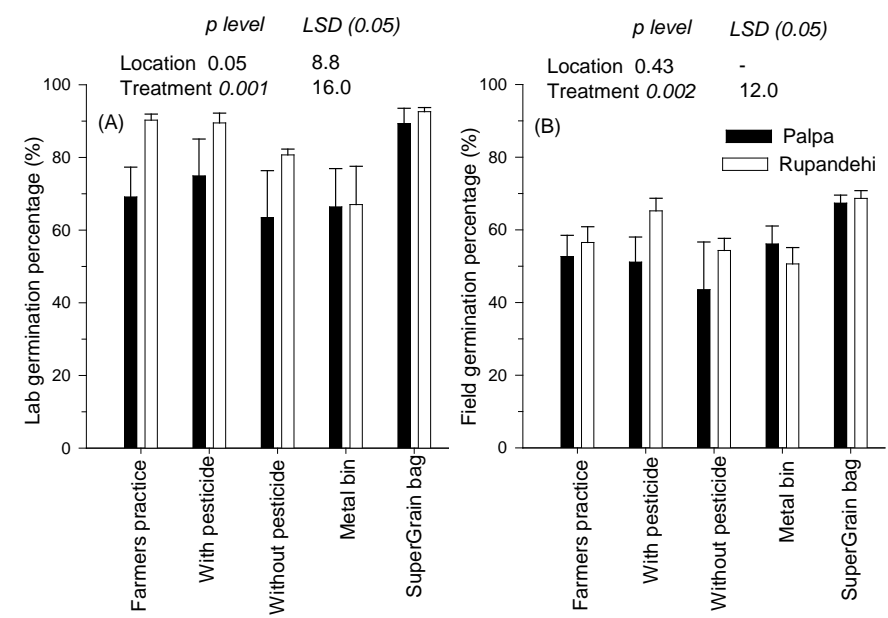

Fig. 3. Variation in laboratory and field germination percentage under different storage treatments in Palpa and Rupandehi.

Similarly, the vigor test resulted is comparable results as the lab germination test for all the storage treatments in the two locations. SGBs showed higher vigor percentage ( 80\%) than other treatments in both the locations. The seed from FP treatment in Palpa resulted in low vigor $(\sim 50 \%)$ while that for the other methods ranged from 60 to $70 \%$ (Fig. 4).

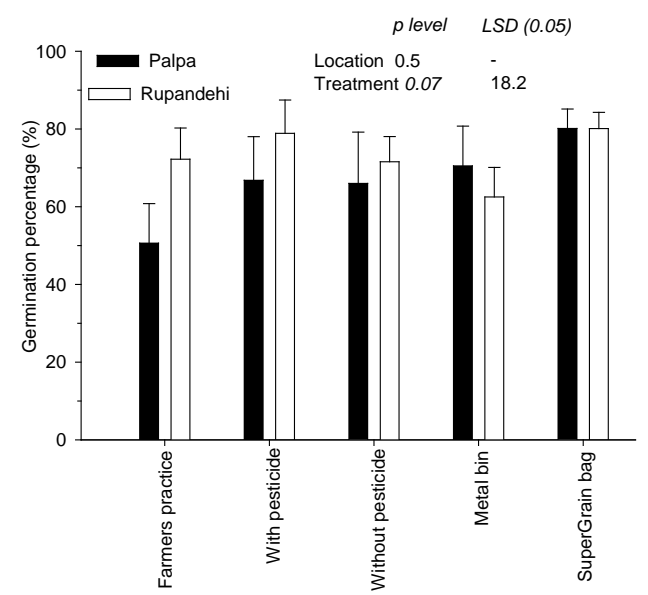

Fig. 4. Variation in seed vigor percentage under different storage method tested in Palpa and Rupandehi.

\section{Cost involved with different storage structures}

The total cost to store per quintal of wheat seed under different methods involves the cost of material and labor used for sun-drying, and storage and fabrication (in case of metal bins) of the storage structure. In terms of individual costs, the initial investment with metal bins was significantly higher ( $\$ 18$ per $100 \mathrm{~kg}$ ) than the other storage structures tested in this study (Fig. 5). The cost of SGBs and FP storage method was $\$ 6$ and $\$ 5$ per $100 \mathrm{~kg}$, respectively, which is one-third of the cost of metal bins. Moreover, the plastic bags with and without pesticide cost less than half of the SGBs and farmers' traditional practice (Fig. 5). 


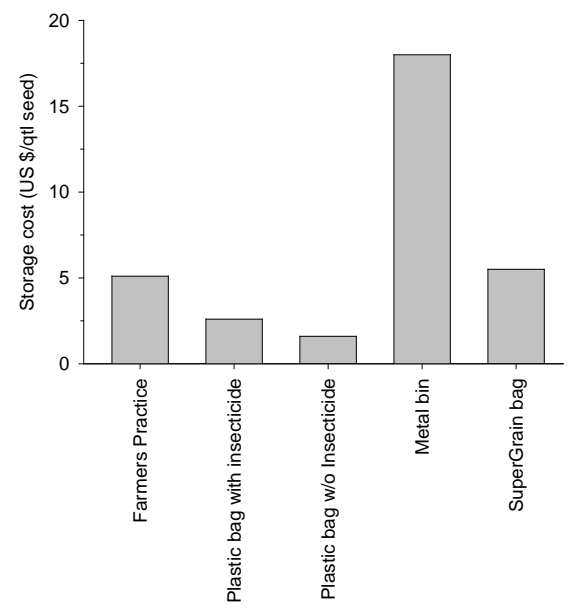

Fig. 5. Variation in cost involved ( $\$$ /qtl. seed stored) for storing per quantal seed under different storage methods.

\section{Discussion}

In the six-month storage period, seed moisture content of all treatments increased. The increment was greater in hills compared to terai plains, which could be related to higher rainfall (Palpa: 2375 mm vs. Rupandehi: $1797 \mathrm{~mm}$ ), more rainy days (Palpa: 85 days vs Rup: 70 days) and lower average temperature (Palpa: $23^{\circ} \mathrm{C}$ vs. Rup: $29^{\circ} \mathrm{C}$ ) during storage period (Fig. 6). Interestingly, lower moisture and insect damage, and better germination percentage were observed under the farmers' method in terai plains. It suggests that farmers can maintain seed quality under ordinary storage structures to some extent in high temperature and low rainfall areas if they frequently check and dry their seed and grain during storage.
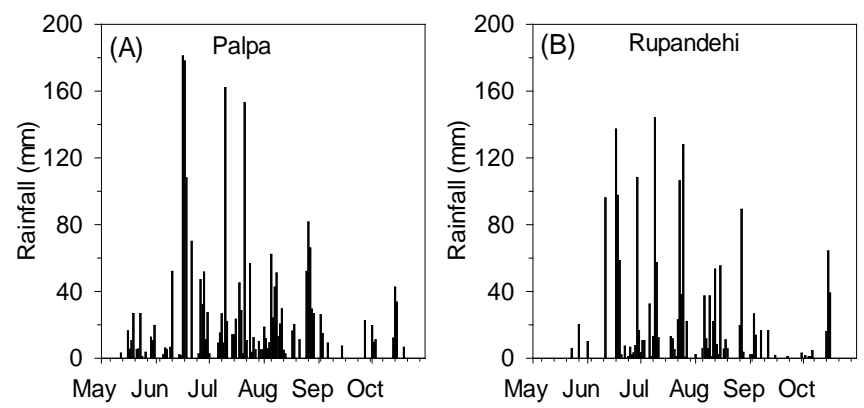

Fig. 6. Daily rainfall in Palpa (A) and in Rupandehi (B) during wheat seed storage period (1 of May to 31 October, 2013).

Seed stored in the SGBs maintained low moisture content with higher seed germination, seed vigor (Fig. 4) and less insect damage (Fig. 2) compared to other storage methods evaluated in both ecologies. It shows that maintaining wheat seed storage quality is more challenging under the ordinary storage method in the hills with higher rainfall and lower temperature than in the terai plains. Further, the higher germination percentage and lower insect infestation under SGB storage was mainly due to maintaining low seed moisture during storage. It is known that every $1 \%$ increase in seed moisture content reduces the seed shelf-life by half (Harrington, 1972). This shows that the hermetic SGBs were mostly successful in preventing moisture migration during storage in both 
ecologies, which was also observed in findings from previous work (Edoh Ognakossan et al., 2013; Navarro et al., 2002). In Kenya, Ndegwa et al. (2016) observed that after four months of storage, grain damage was $14 \%$ in farmers' storage methods and only $4 \%$ in hermetic bags. Baribusta et al. (2014) also found that airtightness of hermetic bags resulted in low oxygen and water vapor permeability, ultimately leading to low grain moisture variation during storage. However, some fluctuation in moisture content was observed in the SGBs, which can be attributed to the loss of air-tightness in storage containers as observed by Chigoverah and Mvumi (2016).

Increased seed moisture content in plastic bags without pesticide in Palpa can be directly linked to higher insect damage (Fig.2), since insects and pests thrive at high moisture conditions. Moreover, the germination percentage for the same was lower than other treatments which can also be ascribed to the higher insect damage. Rodent and insect damage to polypropylene bags has been found to be common in on-farm storage (Ndegwa et al., 2016). The use of a pesticide (celphus) in plastic bags was somewhat effective in reducing insect infestation and maintaining higher germination percentage compared to seed stored in plastic bags without the pesticide. Moreover, the effectiveness of pesticides in controlling insect infestation is well documented (Dales and Golob, 1997; De Groote et al., 2013; Golob et al., 1985). However, use of chemical pesticides in storage may be hazardous if the farmers do not take proper precautions in choosing pesticides and handling them. Again, pesticides may degrade rapidly in tropical climates because of the high temperatures and humidity (Vales et al., 2014).

Metal bins were not able to control insect infestation despite the large investment. The insect damage in the bins was higher compared to other treatments, even the farmers' method (Fig 2), which further led to lower germination (Fig. 3) and vigor of the stored seed (Fig. 4). One of the possible explanations is that the bins were not sufficiently air-tight and the hot and humid climate caused an increase in moisture and in the stress levels of the seed. Another likely reason is believed to be the fact that the bins were only filled up to $\sim 15 \mathrm{~kg}$ when the total capacity was $20 \mathrm{~kg}$, which might have left room for enough oxygen for insects to thrive. Hence, it is strongly advised that standardized procedures such as filling grain or seed up to the brim are followed, and artisan trainings are provided during metal bin fabrication to ensure airtightness of the containers. Chigoverah and Mvumi (2016) found that non-standardization of metal bin fabrication procedure, subjective air-tightness testing, and varying artisan experience may result in variable field performance of the technology. They observed loss of airtightness especially at joints near the inlet. The cost involved for storing seed in SGB was comparable with the farmer's method (Fig. 5) and cheaper than the metal bin, which shows that it can be economical and potentially affordable to the small to medium farmers. For large-scale adoption of hermetic bags, farmers must know or be made aware of the technology, which leads to them expressing their demand for it. It would help if the farmers are in easy geographical reach to make the bags affordable in a sustainable way. Moreover, further communication, awareness programs, and trainings are recommended to inform extension workers and farmers on the importance of drying their seed and grain prior to storage as well as the benefits of hermetic storage. Ndegwa et al. (2016) reported that under basic price, hermetic bags become potentially profitable if they last for four seasons or more, when used for at least four months per season. Among the several hermetic storage bags available in the market, it is important to evaluate their efficiency and durability to maintain seed/grain quality and economics for storing different crops.

\section{Acknowledgements}

We are immensely thankful to the farmers for their cooperation and time, and National Seed Testing Laboratory and National Wheat Research Program (NWRP) for their lab assistance. This work was supported by Agriculture Nutrition and Extension Project (ANEP) funded by European Union (EU) (Grant no. DCI-FOOD/2011/261- 122) and Cereal Systems Initiatives for South Asia (CSISA) funded by USAID (Grant no. BFS-G-11-00002). 


\section{References}

ABdUL-BAKII, A., ANDERSON, J.D., 1973. Vigor determination in Soybean seed by multiple criteria. Crop Sci. 13, 630-633.

AdAMS, J.M. AND G.G.M SCHULTEN, 1978. Losses caused by insects, mites and microorganisms, in: Harris, K.L., Lindblad, C.J. (Eds.), Post Harvest Grain Loss Assessment Methods. American Association of Cereal Chemists, St. Paul, MN, pp. 83-85.

AfZAL, I., BAKHTAVAR, M.A., ISHFAQ, M., SAGHEER, M. AND D. BARIBUTSA, 2017. Maintaining dryness during storage contributes to higher maize seed quality. J. Stored Prod. Res. 72, 49-53. doi:10.1016/j.jspr.2017.04.001

BaOUA, I.B., MARGAM, V., AMADOU, L. AND L.L. MURDOCK, 2012. Performance of triple bagging hermetic technology for postharvest storage of cowpea grain in Niger. J. Stored Prod. Res. 51, 81-85. doi:10.1016/j.jspr.2012.07.003

BARIBUTSA, D., DJiBO, K., LOWENBERG-DeBOER, J., MOUSSA, B. AND I. BAOUA, 2014. The fate of triple-layer plastic bags used for cowpea storage. J. Stored Prod. Res. 58, 97-102. doi:10.1016/j.jspr.2014.02.011

CBS, 2015. Statistical YeAR Book OF NePAL-2015. Government of Nepal, National Planning commission Secretariat, Central Bureau of Statistics, Ramshahpath, Thapathali, Kathmandu.

CHIGOVERAH, A.A. AND B.M MvUMI, 2016. Efficacy of metal silos and hermetic bags against stored-maize insect pests under simulated smallholder farmer conditions. J. Stored Prod. Res. 69, 179-189. doi:10.1016/j.jspr.2016.08.004

DALES, M.J. AND P. GoloB, 1997. The protection of maize against Prostephanus truncatus (Horn), using insecticide sprays in Tanzania. Int. J. Pest Manag. 43, 39-43.

De Groote, H., Kimenju, S.C., Likayo, P., Kanampiu, F., Tefera, T. and J. Hellin, 2013. Effectiveness of hermetic systems in controlling maize storage pests in Kenya. J. Stored Prod. Res. 53, 27-36. doi:10.1016/j.jspr.2013.01.001

EdoH OGNAKOSSAN, K., TOUNOU, A.K., LAMBONI, Y. AND K. HeLL, 2013. Post-harvest insect infestation in maize grain stored in woven polypropylene and in hermetic bags. Int. J. Trop. Insect Sci. 33, 71-81. doi:DOI: 10.1017/S1742758412000458

ELLIS, R.H. AND E.H. ROBERTS, 1980. Improved equations for the prediction of seed longevity. Ann. Bot. 45, 13-30.

FGD, 2017. Focus Group Discussion in Palpa and Rupandehi Districts of Nepal.

Golob, P., Changjareon, P., Ahmed, A., Cox, J., 1985. Susceptibility of Prostephanus truncatus (Horn) to insecticides. J. Stored Prod. Res. 21, 141-150.

GoN, 2013. National Seed Vision. Government of Nepal, Ministry of Agricultural Development, National Seed Board Seed Quality Control Centre, Hariharbhawan, Lalitpur Nepal. doi:http://extwprlegs1.fao.org/docs/pdf/nep147056.pdf

GrAINPRo, 2017. GrainPro [WWW Document]. URL http://grainpro.com/gpi/ (accessed 8.19.17).

HARRINGTON, J.F., 1972. Seed storage and longevity., in: Kozlowski, T.T. (Ed.), Seed Biology. pp. 145-245.

K.C., G., 1992. On farm level pre-harvest and post-harvest food loss preventive system in Nepal, in: Proceeding of National Seminar on Issues and Constraints Related to Post Harvest Food Loss Management. Kathmandu, Nepal.

KIBAR, H., 2015. Influence of storage conditions on the quality properties of wheat varieties. J. Stored Prod. Res. 62, 8-15. doi:10.1016/j.jspr.2015.03.001

MARCOS FILHO, J., 2015. Seed vigor testing: an overview of the past, present and future perspective. Sci. Agric. 72, 363-374. doi:10.1590/0103-9016-2015-0007

MoPE, 2014. Climate data of Nepal. Dep. Hydrol. Meteorol. URL http://www.dhm.gov.np/climate/.

MuRdock, L.L., MARGam, V., BAOUA, I., BALFE, S. AND R.E. ShADE, 2012. Death by desiccation: Effects of hermetic storage on cowpea bruchids. J. Stored Prod. Res. 49, 166-170. doi:10.1016/j.jspr.2012.01.002

Mutungl, C.M., AfFongnon, H., NJoRGE, A.W., BARIBUtSA, D. AND L.L. Murdock, 2014. Storage of mung bean (Vigna radiata [L.] Wilczek) and pigeonpea grains (Cajanus cajan [L.] Millsp) in hermetic triple-layer bags stops losses caused by Callosobruchus maculatus (F.) (Coleoptera: Bruchidae). J. Stored Prod. Res. 58, 39-47. doi:10.1016/j.jspr.2014.03.004

NARC, 2017. Nepal Agriculture Research Council [WWW Document]. Singh Darbur Plaza Marg, Kathmandu, Nepal. URL http://narc.gov.np/org/wheat_research_program.php (accessed 8.19.17).

NAVARRO, S., 2006. Modified atmospheres for the control of stored-product insects and mites, in: Heaps, J.W. (Ed.), Insect Management for Food Storage and Processing. AACC International, St. Paul, MN, pp. 105-146.

Navarro, S., Donahaye, E., Rindner, M., Azrieli, A. AND R. DiAS, 2002. Seed Storage in the Tropics under Gastight Sealed Conditions. 20th ASEAN/2nd APEC Semin. Postharvest Technol. 180-186.

NdegWA, M.K., De Groote, H., GitongA, Z.M. AND A.Y. BRUCE, 2016. Effectiveness and economics of hermetic bags for maize storage: Results of a randomized controlled trial in Kenya. Crop Prot. 90, 17-26. doi:10.1016/j.cropro.2016.08.007

OLAKOJO, S. A. AND T.A. AKINLOSOTU, 2004. Comparative study of storage methods of maize grains in South Western Nigeria. J. Biotechnol. 3, 362-365.

RANA, D., 1997. Guidelines for seed quality control and minimum seed certification standards. HMG/FAO Improv. Seed Qual. Control SERV. PROJ. (TCP/NEP/6611)(FOOD AGRIC. ORGAN. UNITED NATION KATHMANDU).

UTHAYAKUMARAN, S. AND C.W. WRINGLEY, 2010. 4 - Wheat: characteristics and quality requirements BT - Cereal Grains, in: Woodhead Publishing Series in Food Science, Technology and Nutrition. Woodhead Publishing, pp. 59-111. doi:https://doi.org/10.1533/9781845699529.2.59

VALES, M.I., RANGA RAO, G. V., SUDINI, H., PATIL, S.B. AND L.L. MURDOCK, 2014. Effective and economic storage of pigeonpea seed in triple layer plastic bags. J. Stored Prod. Res. 58, 29-38. doi:10.1016/j.jspr.2014.01.004

Villers, P., NavarRo, S., Bruin, T. DE, 2010. New Applications of Hermetic Storage for Grain Storage and Transport. Julius-KühnArchiv 0, 446. doi:10.5073/jka.2010.425.086 